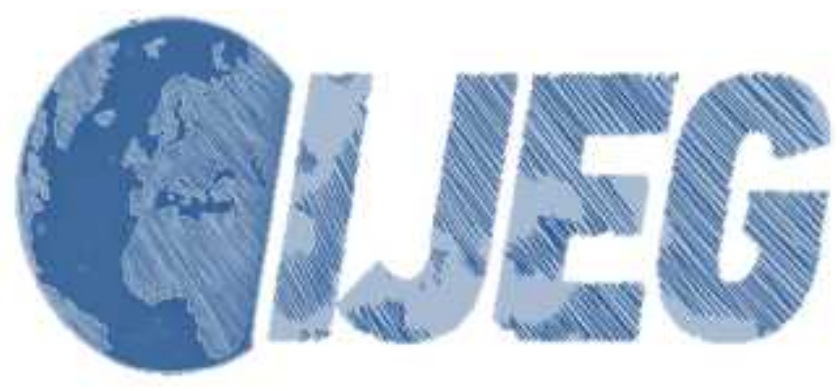

International Journal of Engineering and Geosciences (IJEG), Vol; 4, Issue;1, pp. 036-044, February, 2019, ISSN 2548-0960, Turkey, DOI: 10.26833 ijeg.427531

\title{
ANN APPROACH FOR ESTIMATION OF COW WEIGHT DEPENDING ON PHOTOGRAMMETRIC BODY DIMENSIONS
}

\author{
Sakir Tasdemir ${ }^{1 *}$ and Ilker Ali Ozkan ${ }^{1}$ \\ ${ }^{1}$ Selçuk University, Faculty of Technology, Department of Computer Engineering, Konya, Turkey \\ (stasdemir/ilkerozkan@ selcuk.edu.tr); ORCID 0000-0002-2433-246X; ORCID 0000-0002-5715-1040
}

*Corresponding Author, Received: 27/05/2018, Accepted: 08/07/2018

\begin{abstract}
Computer technology and software are widely used in every multi-discipline field. Geomatics engineering can be seen as a pioneer of these disciplines especially in photogrammetry and image processing. Photogrammetry is a method where geometric parameters of objects on digitally captured images are determined and make measurements on them. Capturing the digital images and photogrammetric processing include several fully defined stages, which allows to generate three-dimension or two-dimension digital models of the body as an end product. The aim of this study is to predict Holstein cows' live weight via artificial neural network whose body dimensions were determined with photogrammetry method. The body dimensions to be used in this study are obtained metric from analysis of cows' images captured by synchronized three-dimension camera environment from different aspects. Wither height, hip height, body length, hip width of cows determined with photogrammetry. Artificial neural network prediction model was developed by using these body measurements. Dataset is divided into two after preprocessing as training and testing dataset. Different structured artificial neural network models are generated and the artificial neural network model which has the best performance is determined. Then with this artificial neural network model live weight of animals is estimated by using measurements obtained from images. After comparison of estimated live weights and weights obtained from scale, correlation coefficient is found $(\mathrm{R}=0.995)$. The statistical analysis shows that both groups are meaningful and artificial neural network can be used in live weight prediction safely.
\end{abstract}

Keywords: Photogrammetry, Image Analysis, Artificial Neural Network, Live weight. 


\section{INTRODUCTION}

There have been new developments in image analysis systems and applications recently. One of the opportunities in these visual applications is that measurements can be made from the obtained images. Contactless analyses of objects are preferred more common than other methods because distortion and changes can happen on the object that will be measured in contact. Computer-aided digital image processing and analysis methods have a great number of application areas in addition to having some advantages such as being time saving, accurate and economic.

Area and length measurements with image analysis can be computed as pixels. These calculations can be made extremely accurate and clear according to the metric system. In order to conduct these analyses according to the metric system, there are a few preprocessing requirements. First process is to find the best calibration parameters explaining camera system. For this process, a particular number of control points in the test are (the reference points whose metric system equals are known) should be created by providing a laboratory environment with a camera system and photographs should be taken. Using these points, transformation process will be performed and the transition from 2-dimensions (2D) to 3-dimensions (3D) or vice versa can be performed. By analyzing these images, length measurements and geometric performances are determined in this way. Thus, metric measurements can be performed as contactless over images with photogrammetry technique (Goktepe, 2010; Tasdemir et. al., 2009; Tudes, 1996; Doğan et.al. 2018).

Image analysis with computer and various prediction applications are commonly used in different disciplines. one of which is husbandry. The number of dairies and their capacity is increasing so the importance of computer-aided studies is gradually increasing and usage of them are being widespread. In dairies, relations among live weight (LW), milk efficiency and forage consume can be accepted as signals for care and nourishment level in business and current animal conditions. It is crucial and necessary to watch these periods. When they are out of the boundaries, this affects the cows' immune system and economic efficiency significantly. Negative changes that can happen in especially live weight may indicate health problems, inappropriate environment conditions and nourishment errors. Therefore, live weight (LW) is certainly important for dairy cows (Tasdemir, 2010).

Artificial Neural Network (ANN) is a rather complex mathematical algorithm that can solve all the problems that are not subject to static mathematical laws. They simulate the way of human brain works in recognizing sounds, words and images. Neural networks can deal with complex issues in a smart way to reach an acceptable degree of expected solutions. The neural network creates interconnected neurons with different weights and each neuron is responsible for one input. For example, we have a problem consisting of ten inputs and one output. When we configure the grid, we actually have created a network of 10 neurons and each neuron responsible for one input. In training, the network continuously adjusts the weights associated with each neuron so that the output is closest to reality. The training process continues on all inputs available and the weights associated with each neuron are adjusted, provided that the resulting value is as close as possible to the true output value. Therefore, the training process and the abundance of information is very important to make the network forecast as close as possible to reality. One of the most important usage area of ANN is used is prediction. ANN can reveal the relations that are unknown among data and hard to notice. Many studies indicate that ANN is used commonly as traditional methods in prediction and it produces better results. For this reason, by using an artificial neural network a model was designed that enables input and output data pattern to be learned by the network.

When the literature reviews are examined, LW predicted studies using regression equations are mostly seen. Artificial intelligence techniques especially LW prediction using ANNs are available for different animal types and for different purposes. Some literature review for LW prediction using ANN; Prediction of bulls' slaughter value from growth data using artificial neural network (Adamczyk et. al., 2005), artificial intelligence technologies in dairy science (Akilli et. al., 2014), comparison of artificial neural network and multiple linear regression for prediction of live weight in hair goats (Akkol et. al., 2017), comparison of artificial neural network and decision tree algorithms used for predicting live weight at post weaning period (Ali et. al., 2015), weight prediction of broiler chickens using 3D computer vision (Mortensen et. al., 2016), prediction of body weight of goats (Raja et. al., 2012), artificial neural network to predict body weights of rabbits (Salawu et. al. 2014), prediction of carcass meat percentage in young pigs using linear regression models and artificial neural networks (Szyndler-Nędza et. al., 2016), walk-through weighing of pigs using machine vision and an artificial neural network (Wang et. al. 2008), extracting the threedimensional shape of live pigs using stereo photogrammetry (Wu et. al., 2004), digital image analysis to estimate the live weights of pigs (Wongsriworaphon at. Al., 2015), estimation of mature live weight using some body measurements in Karya sheep (Yilmaz et. al., 2013).

The aim of this study is to predict LW of cows with artificial neural networks whose body dimension (BD) were determined with photogrammetric method. Thus, images of the cows captured from various angles and BDs were found in $3 \mathrm{D}$ via photogrammetric method. Wither height (WH), hip height (HH), body length (BL) and hip width (HW) of cows were detected with photogrammetry. Besides LW of cows were also measured with a digital scale and saved to computer. ANN prediction model was developed by using these parameters (input parameters are $\mathrm{WH}, \mathrm{HH}, \mathrm{BL}, \mathrm{HW}$ and output parameter is $\mathrm{LW}$ ). At the conclusion predicted LW with ANN and saved LW from scale are compared statistically.

\section{PHOTOGRAMMETRY AND CAMERA CALIBRATION}

Photogrammetry is the technology to obtain quantitative and qualitative information about a region's natural and industrial features by means of photographic or non-photographic images of the area. The pictorial area differs from the ground area in that the ground area deals with nature directly, and the imaging area is to obtain information and measurement of images without direct contact with nature in most stages of work. Photogrammetry uses ways from many department, included projective geometry and optics. Capturing of 
digital image and photogrammetric processing include several fully defined stages, which permit to generate 3D or $2 \mathrm{D}$ digital models of the body as an end product. Figure 1 shows the type of information that can enter and come out of photogrammetric methods.

The 3-D coordinates (or 2-D) determine the locations of body points in the 3-D space. The image coordinates determine the locations of the body points' images on the film. The outer orientation of a camera determines its location in space and its vision direction. The inner orientation determines the geometrical parameters for the imaging process. This is the focal length of the lens but can also include the lens distortions. Photogrammetry algorithms, generally tries to reduce the sum of the squares of errors on the coordinates. This reduction called (bundle adjustment) is known as minimal modification of the beam.

Technical definition of photogrammetry is precise 3D measurement technique over images of objects and metric interpretation of image data. The first step in photogrammetry is to capture images in an intended way. In order to make stereological evaluation, gather 3D data and reach high accuracy, it is essential to capture synchronized images of object in at least two different stations (Figure 1). One of the other conditions to use an image as a measurement image in photogrammetry, is marked points whose 3D coordinates are known on the image are needed. Later, these coordinates are measured from 3D model generated by photogrammetry software. Measurements are done without contact. Photogrammetry that prevents deformation of object and provides safety for measurer, is more efficient and faster compared to classical methods. Images include both metric and semantic information in high density. Apart from the solid and stable objects, dynamic and deformable objects can also be registered and measured (Aguilar et. al., 2005; Atkinson, 1996; Cooper et. al., 1996; Tasdemir et. al., 2008; Tudes, 1996).

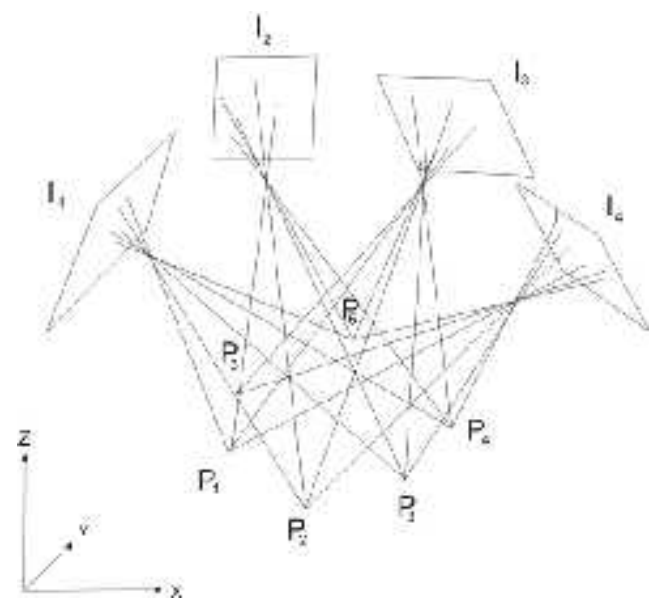

Figure 1. Coordinate of object points $(\mathrm{Pi})$ by triangulating bundles of observation rays from different image planes (Ii)

Before image capturing process studio is prepared, cameras are set in stations and necessary regulations are done. In studio, space coordinates of reference object, whose 3D coordinates are known, are marked and measured. With the help of these measurements, camera calibration and rotation processes can be executed. Later on camera calibration process is executed on prepared experimental test setting (Akçay et. Al., 2017; Tudes 1996; Yilmaz et. al., 2008).

Camera calibration can be defined as finding parameters that represent camera system best. It is compulsory to know geometric performances of the cameras in order to obtain accurate measurements. Geometric accuracy can only be found via calibration of related camera and determining some parameters. These parameters are image capturing distance, directions and angles of image coordinate system axis and distortion parameters. Calibration of a camera can be defined as reverse process of photogrammetric point marking process. In photogrammetric inner orientation elements are known and coordinates of object spots are asked. In calibration on the other hand, coordinates of object spots are known and inner orientation elements are looked for (Atkinson 1996; Goktepe 2010; Karslı ve ark. 2003).

There are many camera calibration methods in literature such as linear, nonlinear and multi-step techniques. Linear method is faster than the others. The most favorite methods in this category is Direct Linear Transformation (DLT), Bundle Adjustment and Tsai's (Roger Tsai's perspective projection camera model) (Tasdemir ve ark. 2009).

To have a transformation between coordination systems, the systems should be described and their status according to each other should be determined. In photogrammetry, measured image coordinates should be transformed to object coordinate system. Image coordinates can be transformed directly into object coordinates via DLT method developed by Abdel-Aziz and Karara. This method defines transformation between image plane and space coordinate system. In the application, relationship between $2 \mathrm{D}$ image plane and $3 \mathrm{D}$ object space coordinate system, is modelled and 11 camera calibration parameters (transformation parameters), which defines cameras, are calculated. Basic DLT equation is shown in Eq. (1) 1 in matrix form.

$\left[\begin{array}{ccccccccccc}X_{1} & Y_{1} & Z_{1} & 1 & 0 & 0 & 0 & 0 & -x_{1} X_{1} & -x_{1} Y_{1} & -x_{1} Z_{1} \\ 0 & 0 & 0 & 0 & X_{1} & Y_{1} & Z_{1} & 1 & -y_{1} X_{1} & -y_{1} Y_{1} & -y_{1} Z_{1} \\ & & & \vdots & & & & & & \vdots & \\ X_{n} & Y_{n} & Z_{n} & 1 & 0 & 0 & 0 & 0 & -x_{n} X_{n} & -x_{n} Y_{n} & -x_{n} Z_{n} \\ 0 & 0 & 0 & 0 & X_{n} & Y_{n} & Z_{n} & 1 & -y_{n} X_{n} & -y_{n} Y_{n} & -y_{n} Z_{n}\end{array}\right]\left[\begin{array}{c}L_{1} \\ L_{2} \\ \vdots \\ L_{0} \\ L_{1}\end{array}\right]=\left[\begin{array}{c}x_{1} \\ y_{1} \\ \vdots \\ x_{n} \\ y_{n}\end{array}\right]$

In order to have mathematical conclusion to the equation, at least 6 point (from two images) whose image coordinates and object coordinates are known, is required. Before calibration object coordinate system of to be measured point and coordinate system of image should be defined. Points object coordinates are named as $\mathrm{X}, \mathrm{Y}, \mathrm{Z}$, image coordinates are named as $\mathrm{x}$, $\mathrm{y}$ and camera calibration parameters are names as $\mathrm{L}_{1}, \mathrm{~L}_{2}, \mathrm{~L}_{3}, \ldots, \mathrm{L}_{11}$ (Abdel-Aziz et. al. 1971; Fang-Jenq,. 1997; Goktepe, 2010; Tasdemir et. Al. 2009). 


\section{IMAGE CAPTURING AND DATASET}

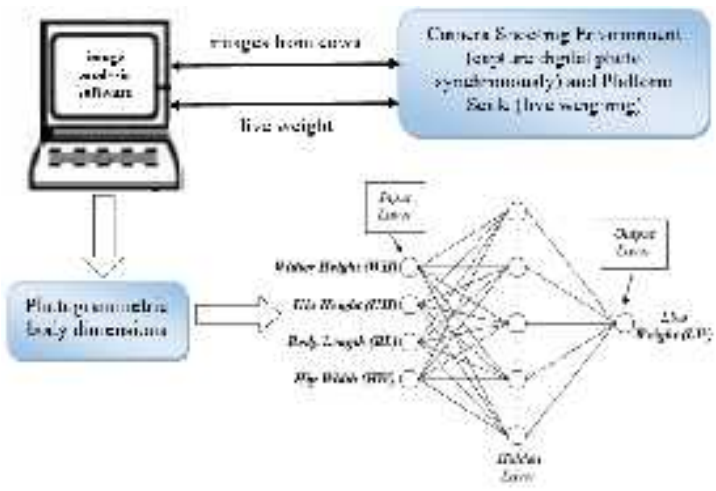

Figure 2. Block diagram of the image capture unit and structure of ANN for LW

A digital photograph shooting studio (platform) designed according to block diagram in Figure 1, is created where lighting system suitable for stereoscopic shooting technique is installed with the help of hardware components. The images of animals captured from both bottom and over with Canon EOS 400D cameras synchronously and at the same time LW of animals measured via digital scale and all data are registered in the computer.

As metric system will be used in measurements, before the computational image capturing process, reference points, whose coordinate numbers are known, were installed the way where animals would pass and be scaled (these points were given coordinates via geodesic methods-spatial coordinates). During installation of the mechanism, since size calculation will be made from analysis of computational images, calibration of appropriately located cameras are done. In this application relationship between $2 \mathrm{D}$ image plane and 3D earth coordination system is modelled and transformation process is executed. Suitable to this relation method, DLT method and camera calibration test area whose 3D coordinates were known, are used to calculate calibration parameters that identifies cameras. On captured images, these reference points whose coordinates were known, and marks were used to calculate animals' body dimensions (wither height (WH), hip height $(\mathrm{HH})$, body length (BL), hip width (HW)) with photogrammetric method via Image Analysis Software (Tasdemir, 2010). LW of cows were also measured with a digital scale and saved to computer. Data set is used in the designed ANN.

Table 1 gives the descriptive statistical results that summarize the numerical values of the data set and convert them to descriptive indexes.

Table 1. Descriptive statistics of data set using ANN

\begin{tabular}{|c|c|c|c|c|c|c|}
\hline 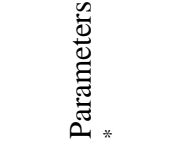 & : & $\begin{array}{l}\Xi \\
\Xi \\
\Xi \\
\Xi\end{array}$ & 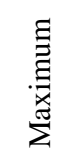 & $\stackrel{\Xi}{\Xi}$ & 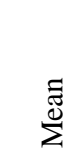 & 离 \\
\hline $\begin{array}{l}\text { Wither Height } \\
(W H)\end{array}$ & $\mathrm{cm}$ & 125 & 149 & 15673 & 136.3 & 4.18 \\
\hline $\begin{array}{l}\text { Hip Height } \\
(H H)\end{array}$ & $\mathrm{cm}$ & 130 & 149 & 16131 & 140.3 & 4.72 \\
\hline
\end{tabular}

\begin{tabular}{ccccccc}
$\begin{array}{c}\text { Body Length } \\
(B L)\end{array}$ & $\mathrm{cm}$ & 148 & 181 & 18889 & 164.3 & 6.34 \\
$\begin{array}{c}\text { Hip Width } \\
(H W)\end{array}$ & $\mathrm{cm}$ & 45 & 65 & 6232 & 54.2 & 3.95 \\
Live Weight & & & & & & \\
\hline
\end{tabular}

$\begin{array}{lllllll}(L W) & \mathrm{kg} & 409.5 & 771 & 65574 & 570.2 & 67.14\end{array}$

${ }^{*} \mathrm{~N}$ (number of data) for each parameter is 115

Dispersion of BDs obtained with photogrammetric technique against live weights measured by digital scale, is given in Figure 3. Data set given in table and figure is used to develop Artificial Neural Network model.

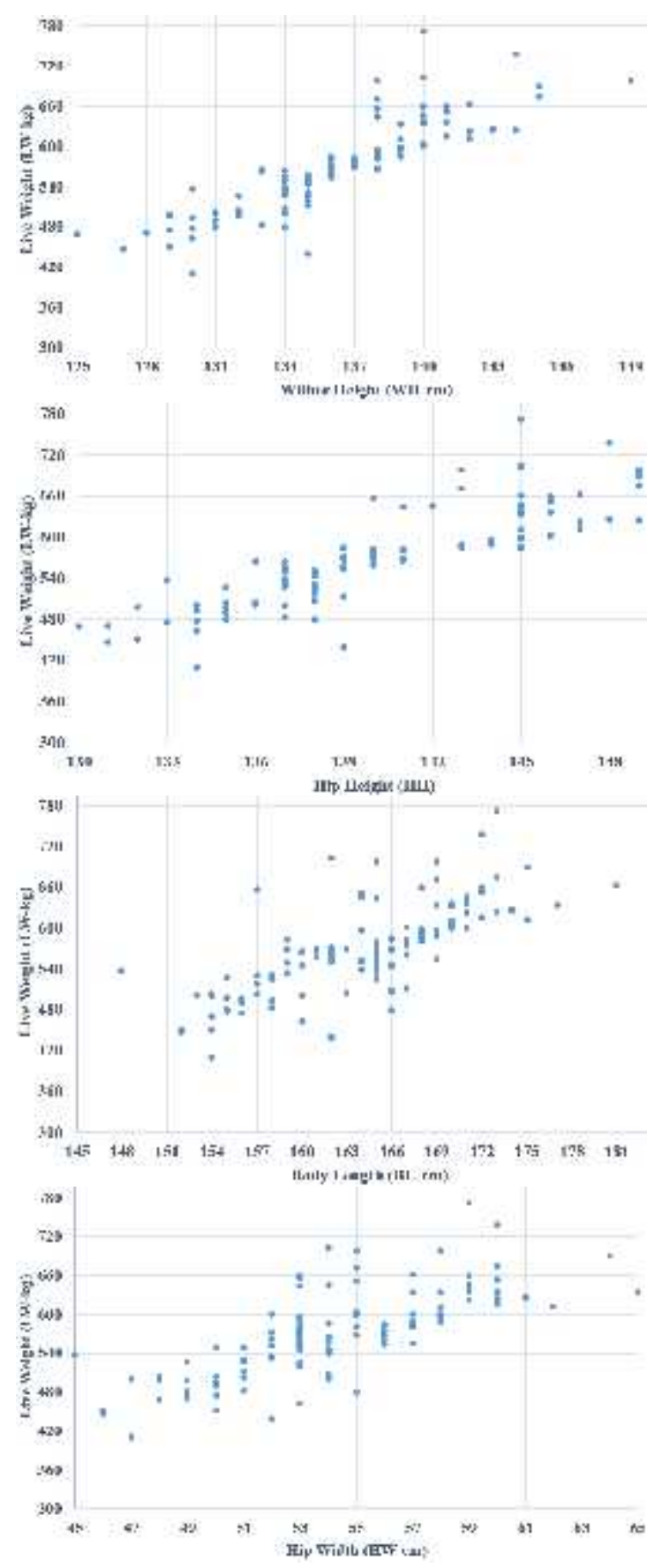

Figure 3. Data set graphics showing dispersion of BDs against live weights 


\section{ARTIFICIAL NEURAL NETWORK (ANN) PREDICTION MODEL AND RESULTS}

Artificial Neural Network (ANN) is an artificial intelligence method fulfilling learning function which is the most basic feature of human brain. ANN has many important features such as learning over examples, producing solutions to non-linear problems, making generalizations, working with missing information and being able to work with infinite number of variance. ANN enables linear and non-linear modelling between input and output variances without requiring any prior knowledge. Thus, ANNs make generalizations from the examples given to themselves during training and they produce information about new samples with these generalizations (Gurney, 2014; Hagan et al., 1996; Maind and Wankar, 2014; Jain et al., 1996; Saritas, 2010)

ANN prediction model is a structure formed through artificial neurons connecting to each other. ANN consists of three main layers as Input Layer, one or more Hidden Layers and Output Layer. Although artificial neurons exist as much as input number of the model, generally inputs are transmitted to interlayers without undergoing any processes. Information going out from the input layer comes to the hidden layer. The number of neurons in hidden layers is independent from the number of input and output. Although the increase of the number of hidden layers and neurons in these layers increase calculation complexity and time, it enables artificial neural network to be used in solutions to more complex problems (Gurney, 2014). The number of hidden layers and neurons in hidden layers are determined with trial and error method. Data are gathered by multiplying their connections weight values in hidden layer and output layer and they are transferred to transfer function. As for output layer, it is the layer producing network outputs by processing the information coming from hidden layers. In ANN with feedback, output produced from this layer is used and new weight values are calculated. (Idris et al., 2017; Maind and Wankar, 2014) ANN prediction model used in this study is shown in Figure 2.

One of the most important factors in an artificial neural network is the connections providing data transfer from one artificial neurons to another. A connection transmitting information from one neuron to another has also a weight value. Add function calculates need input which comes to a neuron. Input is formed for add function by multiplying input variances and weight coefficients. (Altan et al., 2009). A neuron structure is given in Figure 4.

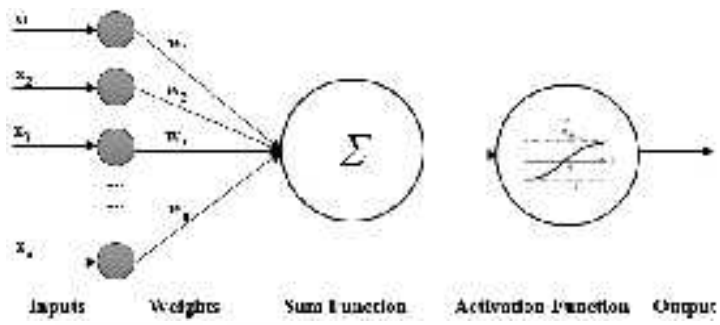

Figure 4. A basic artificial neural network cell

$x_{1}, x_{2}, x_{3} \ldots \ldots x_{n}$ show input values coming to neurons, $w_{1}, w_{2}, w_{3} \ldots . . w_{n}$ show weights of each inputs, b shows bias, y shows output value, in Eq. (2) and (3) where mathematical expression of an artificial neuron is given (Hasni ct al., 2012)

$$
\begin{aligned}
& \text { net }=\sum_{i=1}^{n} w_{i j} x_{j}+b \\
& y=F(n e t)=F\left(\sum_{i=1}^{n} w_{i j} x_{j}+b\right)
\end{aligned}
$$

The alteration in weight values provides ANN's learning process. $\mathrm{F}$ is activation function and is the function that processes the input and generates output.

In order to predict LW with ANN, four inputs which include BDs, were used. These inputs are wither height (WH), hip height $(\mathrm{HH})$, body length (BL), hip width (HW) in order. Data set inputs and outputs normalized between $0-1$ hy using Eq. (4) in order to regulate dispersion of data set values.

$x n=\frac{x_{i}-x_{m i n}}{x_{\max }-x_{\min }}$

$\mathrm{x}_{\mathrm{n}}=$ Normalized $\mathrm{x}_{\mathrm{i}}$ (real value) value

$\mathrm{x}_{\min }=$ Min value of data to be normalized

$\mathrm{x}_{\max }=$ Max value of data to be normalized

Data set consists of $115 \times 5=575$ measurements which include a cow's (BD). Dataset is divided into two parts as $75 \%$ train and $25 \%$ test dataset. As performance function of network Mean Squared Error (MSE) (Tumer et. al., 2015) in Eq. (5) was used.

$M S E=\frac{1}{n} \sum_{k=1}^{n}\left(y_{k}-t_{k}\right)^{2}$

In this equation $y_{k}$ is target or real value, $t_{k}$ is the network output or estimated value and $\mathrm{n}$ is the output data number.

Determining neuron quantity in hidden layer of ANN structure, is important since it states network's generalization ability. In order to determine the neuron quantity in hidden layer MATLAB software is used and various ANN models with different neuron quantities are generated. Figure 5 is MSE variance graph of various ANN models which were generated as a result of changing neuron quantity in hidden layer from 2 to 50 . [4-10-1] structured ANN model whose hidden layer has 10 neurons, has lowest MSE result and is chosen as the most appropriate model to be used in the study.

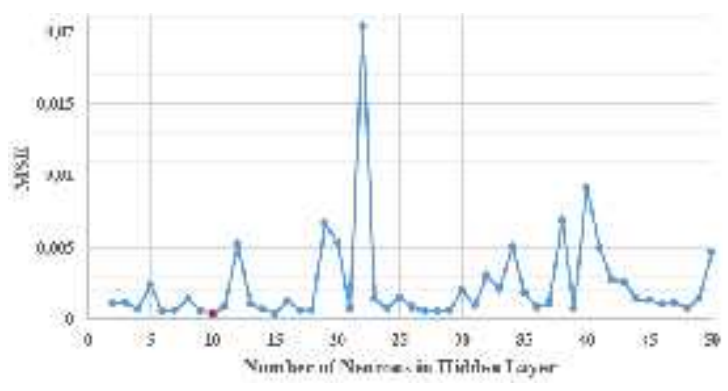

Figure 5. MSE variance for different ANN structures

In this study according to body dimensions (WH, HH, $\mathrm{BL}$, and $\mathrm{HW}$ ) of cows, live weight of cow is predicted. BDs used in the study are obtained via photogrammetric methods. In literature various methods were used to determine the live weight of cows. In this study an ANN prediction model, which can predict live weight of animal 
according to its BDs, is generated since it can model linear relations along with non-linear relations in data set successfully and it has no need for any presupposition over data.

In Table 2'de parameters of chosen ANN structure are given.

Table 2. ANN Parameters

\begin{tabular}{ll}
\hline Hidden Layer Number & 1 \\
Activation Function, Hidden Layer & Tansig \\
Activation Function, Output Layer & Lineer \\
Learning Rate & 0.01 \\
Minimum performance gradient & $1 \mathrm{e}-5$ \\
Performance goal & $1 \mathrm{e}-3$ \\
Maximum number of epochs to train & 5000 \\
\hline
\end{tabular}

Correlation Coefficient (R) is used to evaluate the performances measured LW and predicted values. R value changes from 0 to 1 , the stronger the relation between value calculated with model and value measured. In other words, The closer the $\mathrm{R}$ value to 1 , the more successful the model's prediction ability (Cohen et al., 2013).

In the study [4-10-1] structured ANN model is used and 0.9916 (for testing), 0.9963 (for training) and 0.9949 (training and testing) correlation coefficient $(\mathrm{R})$ values are obtained in test dataset, train dataset and all dataset in order. Linear regression graphics of network outputs according to weights are given in Figure 6.
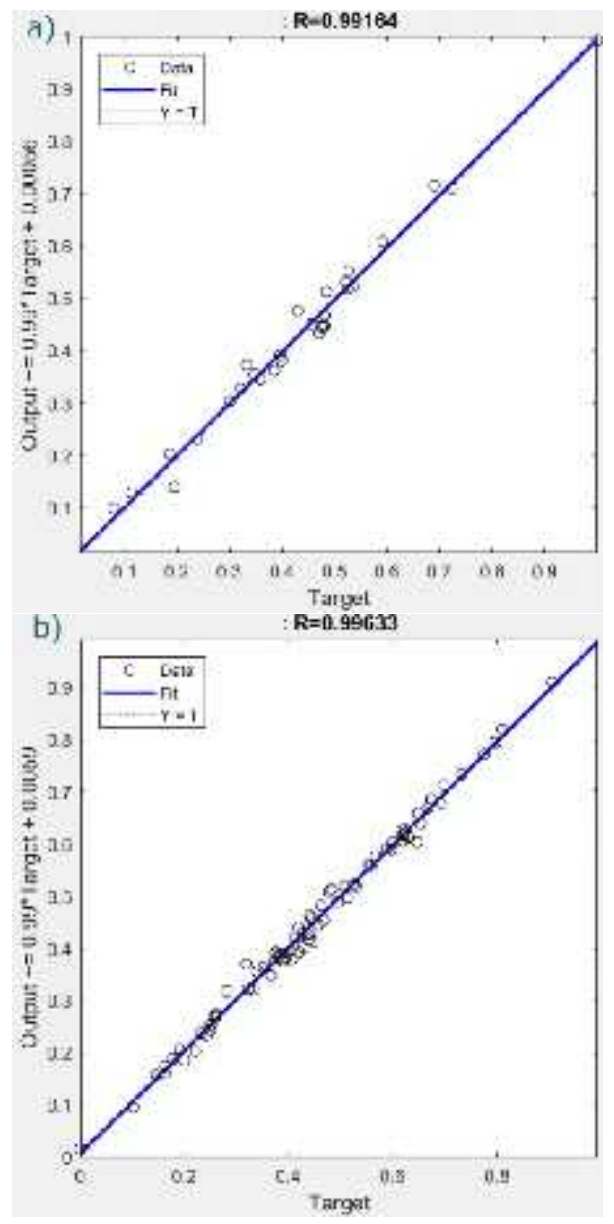

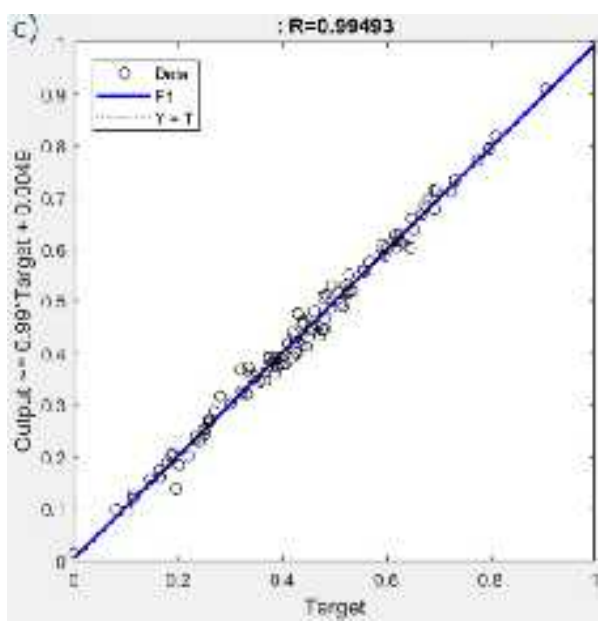

Figure 6. Linear regression graphics a) Testing dataset b) Training dataset c) Training and Testing dataset (all)

In Figure 7 for 115 data example comparison of LW scale values and ANN model prediction values are given graphically.

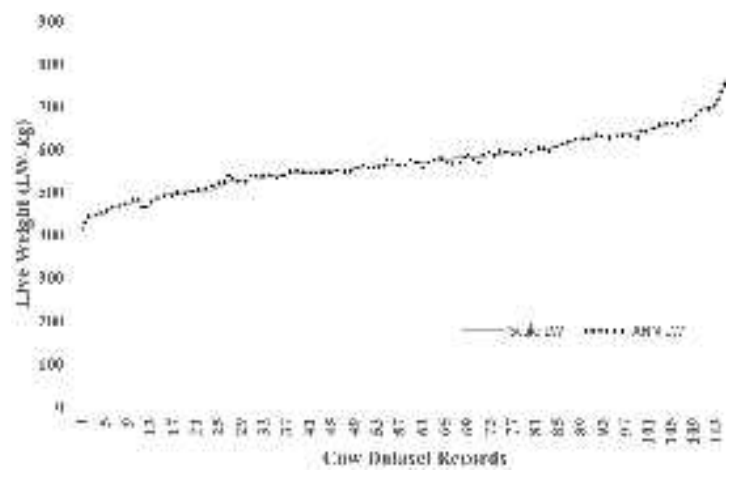

Figure 7. LW Scale and ANN prediction values variation

In this study Eq. (6) is used to predict LW according to BDs with ANN model.

ANN Prediction $=$ denorm $\left(w_{2}, \operatorname{tansig}\left(u_{1} .[x(1) ; x(2) ; x(3) ; x(4)]+\right.\right.$ $\left.\left.b_{1}\right)+b_{2}\right)$

In this equation $\mathrm{x}(1), \mathrm{x}(2), \mathrm{x}(3)$ ve $\mathrm{x}(4)$ variations show $\mathrm{WH}, \mathrm{HH}, \mathrm{BL}, \mathrm{HW}$ values respectively, $\mathrm{w}_{1}$ ve $\mathrm{b}_{1}$ show weight and bias in hidden layer, w2 ve b2 show LW and bias in output layer. In Table 3 weight and bias values for every layers obtained from optimum ANN structure, are given. Besides, aforementioned tansig and denorm functions are given in Eq. (7) and (8).

$\operatorname{tansig}(n)=\frac{2}{\left\langle 1+e^{-2 \pi}\right)}-1$

denorm $(n)=n 361.5+409.5$ 
Table 3. ANN's weight and bias values for LW

\begin{tabular}{|c|c|c|c|c|c|c|}
\hline \multicolumn{4}{|c|}{$\mathrm{w}_{1}$} & \multirow{2}{*}{$\begin{array}{l}\left(\mathrm{w}_{2}\right)^{\mathrm{T}} \\
0.52\end{array}$} & \multirow[t]{2}{*}{$\mathrm{b}_{1}$} & $\mathrm{~b}$ \\
\hline & & & - & & & 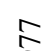 \\
\hline 1404 & 059 & 590 & 855 & 0.20 & 84 & J \\
\hline 3.15 & 0.36 & 0.96 & 1.90 & 763 & - & \\
\hline \multirow[t]{2}{*}{654} & 502 & 831 & 868 & 0.51 & 1.599 & \\
\hline & & - & & 140 & 58 & \\
\hline 0.65 & 1.03 & 1.83 & 1.32 & 0.82 & - & \\
\hline 207 & 833 & 813 & 029 & 795 & 2.137 & \\
\hline- & - & & - & 0.19 & 91 & \\
\hline 1.04 & 0.68 & 1.01 & 0.09 & 490 & 1.456 & \\
\hline \multirow{2}{*}{395} & 947 & 252 & 592 & 1.09 & 80 & \\
\hline & & - & - & 210 & 0.620 & \\
\hline 0.24 & 0.86 & 1.54 & 1.66 & - & 41 & \\
\hline 973 & 463 & 535 & 778 & 0.24 & - & \\
\hline- & - & - & & 687 & 0.842 & \\
\hline 0.57 & 0.84 & 0.13 & 1.97 & 0.54 & 07 & \\
\hline 314 & 760 & 942 & 171 & 190 & 0.403 & \\
\hline- & - & - & & 0.59 & 49 & \\
\hline 1.51 & 3.00 & 1.21 & 2.22 & 424 & 1.696 & \\
\hline \multirow[t]{2}{*}{778} & 138 & 291 & 314 & 0.94 & 79 & \\
\hline & - & - & - & 914 & - & \\
\hline 2.19 & 0.94 & 1.18 & 1.77 & & 2.650 & \\
\hline 149 & 908 & 213 & 171 & & 61 & \\
\hline- & - & - & - & & 1.891 & \\
\hline 0.63 & 2.24 & 1.73 & 0.05 & & 76 & \\
\hline \multirow[t]{2}{*}{997} & 131 & 209 & 444 & & & \\
\hline & & & - & & & \\
\hline 1.25 & 1.45 & 0.91 & 0.18 & & & \\
\hline 102 & 673 & 481 & 310] & & & \\
\hline
\end{tabular}

Moreover, according to result of t-test conducted in SPSS statistical analysis software in 95\% reliability interval, there is no meaningful difference between ANN prediction values and LW values. As in table 4 the mean level is 0.994 which is high and reliable.

Table 4. t-Test for equality of means

\begin{tabular}{|c|c|c|c|c|c|c|}
\hline \multirow{2}{*}{-} & \multirow{2}{*}{ 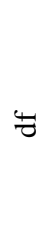 } & \multirow{2}{*}{ 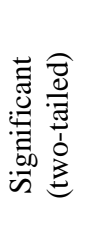 } & \multirow{2}{*}{ 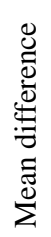 } & \multirow{2}{*}{ 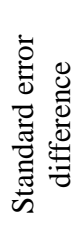 } & \multicolumn{2}{|c|}{$\begin{array}{l}\text { 95\% Confidence } \\
\text { interval of the } \\
\text { difference }\end{array}$} \\
\hline & & & & & 离 & 离 \\
\hline \begin{tabular}{l}
$\infty$ \\
\multirow{8}{0}{} \\
0
\end{tabular} & ลิ & $\hat{o}$ & ọ & $\begin{array}{l}\infty \\
\infty \\
\infty\end{array}$ & כ. & $\stackrel{m}{\stackrel{m}{I}}$ \\
\hline
\end{tabular}

\section{CONCLUSION}

In this study, ANN study with four inputs and one output was performed to predict LW using body dimensions of cows. The use of ANN is a useful model in this study due to the nonlinear data. The model of live weight prediction is useful and necessary in this kind of animals, because scale is a difficult way to measure LW and animals feel stressed on scale. In this study LW values obtained from ANN and scale measurements were compared. It is seen that there is a consistency between two groups of data through comparison. ANN produced successful results, and can be used in such kind of system modelling and prediction (Table 4). It has been observed that there is a strong correlation between the estimated LW data by ANN and the measured data with scale.

Analysis and comparisons made based on the consistency between the values obtained this way.

Prediction accuracy increases when the correlation coefficient value is close to 1 . In this study, obtained correlation coefficients are very close to 1 for all the dataset which indicates that there is a perfect match between ANN prediction values and live weight values. Correlation coefficient for ANN prediction value in the test data set was found as 0.9916 for testing and $\mathrm{R}$ has an acceptable value.

When input parameter numbers are increased in designed model, the success rate of the study is thought to increase. What is more, this developed method and modelling can be used to measure weights of different kinds of species. When another smart system, algorithm, mathematical and statistical method are used alone or with ANN instead of ANN used in the study, it can affect the rate of success. In addition, this model has the skill of predicting LW values which are not found in data set.

\section{REFERENCES}

Abdel-Aziz, Y.I. ve Karara, H.M. (1971). Direct Linear Transformation from Comparator Coordinates into Object Space Coordinates in Close-Range Photogrammetry, Proceedings of the Symposium on Close-Range Photogrammetry, Urbana, Illinois, 1-8.

Adamczyk, K., Molenda, K., Szarek, J., \& Skrzyński, G. (2005). Prediction of Bulls'slaughter Value From Growth Data Using Artificial Neural Network. Journal of Central European Agriculture, 6(2), 133-142.

Aguilar, M. A., Aguilar, F. J., Agüera, F., \& Carvajal, F. (2005). The evaluation of close-range photogrammetry for the modelling of mouldboard plough surfaces. Biosystems Engineering, 90(4), 397-407.

Akçay, Ö., Erenoğlu, R , Avşar, E . (2017). The Effect of Jpeg Compression in Close Range Photogrammetry. International Journal of Engineering and Geosciences, 2 (1), 35-40. DOI: 10.26833/ijeg.287308

Akilli, A., \& Atil, H. (2014). Artificial Intelligence Technologies in Dairy Science: Fuzzy Logic and Artificial Neural Network. Hayvansal Üretim, 55(1), 3945.

Akkol, S., Akilli, A., \& Cemal, . (2017). Comparison of Artificial Neural Network and Multiple Linear Regression for Prediction of Live Weight in Hair Goats.YYU Yüzüncü Y1l Üniversitesi Journal of Agricultural Sciences, 27(1), 21-29.

Ali, M., Eyduran, E., Tariq, M. M., Tirink, C., Abbas, F., Bajwa, M. A., ... \& Shah, S. H. (2015). Comparison of artificial neural network and decision tree algorithms used for predicting live weight at post weaning period from some biometrical characteristics in Harnai sheep. Pakistan J. Zool., vol. 47(6), pp. 1579-1585. 
Atkinson, K.B. (1996). Close Range Photogrammetry and Machine Vision, Whittles Publishing, Scotland, 1996.

Altan, Ö., Gölcü, M. (2009). Daily means ambient temperature prediction using artificial neural network method: A case study of Turkey. Renewable Energy 34, $1158-1161$

Cohen, J., Cohen, P., West, S.G., Aiken, L.S. (2013). Applied multiple regression/correlation analysis for the behavioral sciences. Routledge.

Cooper, M. A. R. and Robson, (1996). S.Theory of Close Range Photogrammetry, Close Range Photogrammetry and Machine Vision, 9-51.

Doğan, Y., Yakar, M. (2018). GIS and three-dimensional modeling for cultural heritages. International Journal of Engineering and Geosciences, 3 (2), 50-55.

Fang-Jenq, C. (1997). Application of Least-Squares Adjustment Technique to Geometric Camera Calibration and Photogrammetric Flow Visualization, ISA 43rd International Instrumentation Symposium, Orlando, Florida.

Goktepe, A. (2010). A study on the calibration of stereo photogrammetric systems used in motion analysis. Scientific Research and Essays, 5(17), 24912496

Gurney, K. (2014). An introduction to neural networks. CRC press.

Hagan, M.T., Demuth, H.B., Beale, M.H. (1996). Neural network design. Pws Pub. Boston.

Hasni, A., Sehli, A., Draoui, B., Bassou, A., Amieur, B. (2012). Estimating Global Solar Radiation Using Artificial Neural Network and Climate Data in the Southwestern Region of Algeria. Energy Procedia 18, 531-537.

Idris, N.H., Salim, N.A., Othman, M.M., Yasin, Z.M. (2017). Prediction of Cascading Collapse Occurrence due to the Effect of Hidden Failure of a Protection System using Artificial Neural Network. Journal of Electrical Systems 13.

Jain, A.K., Jianchang, M., Mohiuddin, K.M. (1996). Artificial neural networks: a tutorial. Computer 29, 31-44.

Karsli, E., Ayhan, E., Tunc, E. (2003). Genelleştirilmiş DLT metodu ile Dijital Kamera Geometrik Kalibrasyonu, TMMOB Harita ve Kadastro Mühendisleri Odası 9. Türkiye Harita Bilimsel ve Teknik Kurultayı, Ankara.

Maind, S.B., Wankar, P. (2014). Research paper on basic of artificial neural network. International Journal on Recent and Innovation Trends in Computing and Communication 2, 96-100.

Mortensen, A. K., Lisouski, P., \& Ahrendt, P. (2016). Weight prediction of broiler chickens using 3D computer vision. Computers and Electronics in Agriculture, 123, 319-326.
Raja, T. V., Ruhil, A. P., \& Gandhi, R. S. (2012). Comparison of connectionist and multiple regression approaches for prediction of body weight of goats. Neural Computing and Applications, 21(1), 119-124.

Salawu, E. O., Abdulraheem, M., Shoyombo, A., Adepeju, A., Davies, S., Akinsola, O., \& Nwagu, B. 2014. Using artificial neural network to predict body weights of rabbits. Open Journal of Animal Sciences, 4(04), 182.

Saritas, I., Ozkan, I. A., \& Sert, I. U. (2010). Prognosis of prostate cancer by artificial neural networks. Expert Systems with Applications, 37(9), 6646-6650.

Szyndler-Nędza, M., Eckert, R., Blicharski, T., Tyra, M., \& Prokowski, A. (2016). Prediction of carcass meat percentage in young pigs using linear regression models and artificial neural networks. Annals of Animal Science, 16(1), 275-286.

Tasdemir, S., Yakar, M., Urkmez, A., \& Inal, S. (2008, June). Determination of body measurements of a cow by image analysis. In Proceedings of the 9th International Conference on Computer Systems and Technologies and Workshop for PhD Students in Computing (p. 70). ACM.

Tasdemir, S., Urkmez, A., Yakar, M. ve Inal, S, 13-15 May 2009. Determination of camera calibration parameters at digital image analysis. IATS'09.

Tasdemir, S. (2010). Determination of Body Measurements On the Holstein Cows by Digital Image Analysis Method and Estimation of Their Live Weight. $\mathrm{Ph}$. D. thesis, Selcuk University, Konya, Turkey.

Tudes, T., Yer Fotogrametrisi, (1986). KTÜ Basımevi, Mühendislik Fakültesi yayını, No: 105, Trabzon, 1996.

Tumer, A. E., \& Edebali, S. (2015). An Artificial Neural Network Model for Wastewater Treatment Plant of Konya. International Journal of Intelligent Systems and Applications in Engineering, 3(4), 131-135.

Wang, Y., Yang, W., Winter, P., \& Walker, L. (2008). Walk-through weighing of pigs using machine vision and an artificial neural network. Biosystems Engineering, 100(1), 117-125.

Wu, J., Tillett, R., McFarlane, N., Ju, X., Siebert, J. P., \& Schofield, P. (2004). Extracting the three-dimensional shape of live pigs using stereo photogrammetry. Computers and Electronics in Agriculture, 44(3), 203-222.

Wongsriworaphon, A., Arnonkijpanich, B., \& Pathumnakul, S. (2015). An approach based on digital image analysis to estimate the live weights of pigs in farm environments. Computers and Electronics in Agriculture, 115, 26-33.

Yilmaz, H. M., Yakar, M., Yildiz, F. 2008. Digital Photogrammetry in Obtaining of 3D Model Data of Irregular Small Surfaces Objects. ISPRS Congress, Beijing, 125-130. 
International Journal of Engineering and Geosciences (IJEG), Vol; 4, Issue; 1, pp. 036-044, February, 2019,

Yilmaz, O., Cemal, I., \& Karaca, O. (2013). Estimation of mature live weight using some body measurements in Karya sheep. Tropica. 